\title{
O Brasil e o sistema mundial de poderes
}

\section{ANTÔNIO JOSÉ FERNANDES*}

\section{Introdução}

Sem se situar numa perspectiva sistêmica, Raymond Aron (1962) definiu o sistema internacional como "um conjunto constituído por unidades políticas que mantêm entre si relações regulares e que todas são susceptíveis de ser implicadas numa guerra geral”. É a intensidade das relações regulares, que unem ou opõem os elementos constitutivos do conjunto, que distingue o sistema do seu ambiente, conforme sublinhou M. Kaplan (1975). De acordo com este autor, as relações regulares - susceptíveis de ser relações conflituosas - que unem a Rússia aos outros grandes Estados europeus desde o século XVIII, incluem este país no sistema europeu.

A perspectiva sistêmica olha para a comunidade internacional pela ótica macro-estrutural. Atribui às grandes estruturas do sistema internacional a qualidade de variável independente essencial, explicativa do tipo de relações que se desenrolam entre as unidades constitutivas do sistema. Assim, a multipolaridade ou a bipolaridade definem o tipo de comportamento dos Estados, e a maior ou menor estabilidade do sistema internacional depende da estrutura de base do sistema - equilíbrio de forças multipolar, tripolar, bipolar, etc.

A perspectiva sistêmica aplicada à comunidade internacional caracterizase por um certo grau de abstração, na medida em que o sistema internacional não dispõe de um centro político capaz de engendrar outputs em termos de decisão. As insatisfações dos Estados tornam-se os inputs do sistema. E a resposta a essas insatisfações tem de ser encontrada na própria estrutura do sistema, onde os Estados (subsistemas) têm mais capacidade de ação do que a coletividade mundial (sistema). Porque as lealdades são nacionais, o sistema internacional dispõe de poucos apoios e recursos. Por outro lado, o sistema mundial de poderes inscrevese num ambiente de ordem ideológica, religiosa, tecnológica, geográfica, etc., e tudo o que é estranho à vida política internacional participa, por isso, no seu ambiente e condiciona a estrutura do sistema. As solidariedades e as tensões regionais 
subjacentes a um subsistema (ou sistema subordinado) influem no equilíbrio global da estrutura do sistema mundial.

A aplicação da análise sistêmica às relações internacionais permite-nos ver a comunidade mundial como um todo (sistema) constituído por diversos elementos (subsistemas) de dimensões e força variadas. A comunidade internacional é, assim, identificada com um sistema global constituído por subsistemas regionais, que, por sua vez, integram outros subsistemas (os Estados). É a inter-relação dos diversos subsistemas que caracteriza e tipifica o sistema internacional.

Se a análise sistêmica permite interpretar, compreender e explicar a comunidade internacional como um sistema global integrado por diversos subsistemas (alguns dos quais os Estados), como se explica a evolução do sistema mundial de poderes? Como se caracterizam os sistemas bipolares que marcaram determinados períodos da história das relações internacionais? E como se caracteriza o sistema mundial de poderes do final do século XX e início do século XXI? E qual a posição e o papel do Brasil no contexto deste sistema?

\section{Aplicação da análise sistêmica à comunidade internacional}

A primeira aplicação da análise sistêmica ao domínio internacional foi tentada por Morton Kaplan através da sua obra System and Process in Internacional Politics (1975).

Partindo do princípio de que na cena internacional não existe um centro de poder comparado ao poder dos Estados nas sociedades nacionais e admitindo que os Estados, particularmente as grandes potências, tendem a preencher esse vazio de poder, Morton Kaplan distinguiu seis tipos de sistema internacional: sistema de balança de poderes; sistema bipolar rígido; sistema bipolar flexível; sistema hierárquico; sistema universal; e sistema de veto nacional.

Relativamente ao primeiro sistema (sistema de balança de poderes), o autor limita-se a traduzir para a linguagem sistêmica a literatura tradicional sobre o equilíbrio de forças, fazendo o mesmo em relação aos sistemas hierárquico e universal mediante o recurso à literatura federalista ou da integração política internacional; e no que respeita ao sistema de veto nacional adaptou à linguagem sistêmica a literatura sobre a dissuasão nuclear.

Contudo, Kaplan deu um contributo específico à compreensão da bipolaridade, cuja análise expressou em linguagem diferente da habitual.

Alguns dos tipos de sistema internacional indicados por Kaplan tiveram ou têm um suporte histórico (o sistema de balança de poderes e o sistema bipolar flexível); outros são puras projeções do espírito (os sistemas bipolar rígido, universal e hierárquico); e o outro pode ser uma antecipação da realidade internacional (o sistema de dissuasão nuclear generalizada ou sistema de veto nacional). 
Nesta perspectiva, interessa efetivamente analisar a realidade histórica contemporânea, com particular relevância para a evolução do sistema mundial depois da Segunda Guerra Mundial, quer dizer, o sistema bipolar e o sistema multipolar (ou multiblocos).

\section{Os sistemas bipolares}

Os modelos bipolares têm sido raros ao longo da história, e foram sempre intercalados por configurações unipolares ou multipolares.

Antes da bipolaridade contemporânea subjacente à II Guerra Mundial, apenas se contam, no mundo ocidental, as situações bipolares que opuseram Esparta a Atenas (tornada célebre pelas guerras do Peloponeso), Roma a Cartago (guerras púnicas), a Espanha a Portugal (Tratado de Tordesilhas), a França à Espanha (século XVIII), a Tríplice Aliança à Triple Entente (desde 1907 até ao fim da primeira Guerra Mundial).

\section{Quadro 1}

Evolução dos sistemas mundiais de poderes

\begin{tabular}{|c|c|c|c|}
\hline Períodos & Sistemas Bipolares & Sistemas Unipolares & Sistemas Multipolares \\
\hline Séc. V a.C. ................. & Esparta - Atenas & & \\
\hline Séc. IV a.C. ................ & & Império Persa & \\
\hline Séc. III e II a.C. .......... & Roma - Cartago & & \\
\hline Séc. I a.C. .................. & & Império Romano & \\
\hline Séc. V d.C. ................. & & & Reinos e Repúblicas \\
\hline 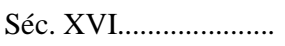 & Espanha - Portugal & & \\
\hline Séc. XVII....................... & & & Monarquias Absolutas \\
\hline Séc. XVIII.................... & Espanha - França & & \\
\hline 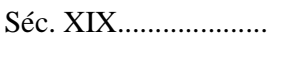 & & & $\begin{array}{l}\text { Equilíbrio de poderes } \\
\text { (Concerto Europeu) }\end{array}$ \\
\hline 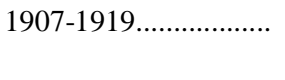 & $\begin{array}{l}\text { Tríplice Aliança - } \\
\text { Triple Entente }\end{array}$ & & \\
\hline 1919-1939..................... & & & $\begin{array}{l}\text { Sistema de Segurança } \\
\text { Coletiva (SDN) }\end{array}$ \\
\hline 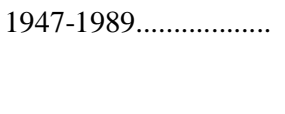 & $\begin{array}{l}\text { EUA (Bloco Ocidental } \\
\text { - URSS (Bloco Leste) } \\
\text { (bipolarização flexível) }\end{array}$ & & \\
\hline 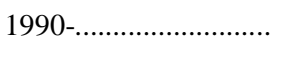 & & & $\begin{array}{l}\text { Sistema multipolar } \\
\text { (ou multiblocos) }\end{array}$ \\
\hline
\end{tabular}


Todos estes sistemas bipolares foram intercalados por sistemas unipolares ou multipolares, como se indica no quadro $\mathrm{n}^{\circ} 1$ relativo à evolução dos sistemas mundiais de poderes.

Os sistemas bipolares indicados neste quadro não apresentam todos as mesmas características e, por isso, não são do mesmo tipo. De fato, estão ali representados três tipos de sistemas bipolares: a bipolaridade real entre dois Estados (Roma-Cartago); a bipolarização de um sistema multipolar (Tríplice Aliança-Triple Entente); e a bipolarização flexível contemporânea (Bloco Ocidental - Bloco Leste).

Como notou Hans Morgenthau (1969), "os sistemas multipolares têm tendência a bipolarizar-se”. No entanto, os sistemas bipolares surgidos até ao século XX caracterizaram-se pelo fato da bipolarização assentar em dois Estados; enquanto as bipolarizações do século XX se caracterizam pela coexistência de dois grupos de Estados (alianças ou blocos). Contudo, o sistema bipolar do princípio do século era muito diferente do sistema bipolar flexível instituído a partir de 1947. No primeiro, não existiam dois Estados com um poderio muito superior ao dos outros que lhes permitisse tornarem-se os pólos do sistema (os dois pólos eram constituídos pela Alemanha, Áustria e Itália, de um lado, e pela França, Inglaterra e Rússia, do outro) - a oposição era entre as duas alianças (blocos). No segundo, os EUA e a URSS constituem os pólos de cada um dos blocos (Aliança Atlântica e Pacto de Varsóvia) que ajudaram a construir ou que foram criados sob a sua inspiração e apoio - a oposição manifesta-se entre dois Estados (os dois pólos) e entre duas alianças (os dois blocos).

Analisando os sistemas bipolares, Morton Kaplan distinguiu a bipolaridade rígida da bipolaridade flexível. O sistema bipolar rígido é completamente bipolarizado: todos os Estados, sem excepção significativa, são alinhados por um ou outro dos blocos. O sistema bipolar flexível é aquele em que a bipolarização não foi alcançada completamente: uma parte dos agentes políticos internacionais fica fora do sistema - os não alinhados.

Assim, na perspectiva de Kaplan, o sistema bipolar flexível da última metade do século XX caracterizava-se estruturalmente pela coexistência de quatro tipos principais de atores (agentes) internacionais:

- os pólos (EUA e URSS): dois atores nacionais essenciais;

- os blocos (NATO e Pacto de Varsóvia): dois atores transnacionais;

- a ONU: um ator universal;

- os Não Alinhados: os Estados não comprometidos com nenhum dos blocos.

E cada um destes tipos de atores adotava formas particulares de comportamento político-diplomático, sendo os blocos os atores mais característicos 
do sistema bipolar. Distinguiam-se do ator universal pelo seu caráter regional, e diferenciavam-se nitidamente das alianças tradicionais, já que eram alianças duráveis, militarmente organizadas a partir do tempo de paz, enquanto as alianças tradicionais não são mais do que obrigações jurídicas de ajuda mútua. Os blocos eram (são), pois, organizações internacionais de defesa e de segurança, cuja característica principal era a de estarem articulados com um dos pólos de bipolaridade.

\section{O sistema multipolar contemporâneo (ou sistema multiblocos)}

Alguns autores, baseando-se na proliferação das armas nucleares, na dispersão das potencialidades atômicas e na importância do elemento econômico no contexto do Poder, concluíram que a bipolaridade contemporânea suscitou um ambiente internacional policêntrico (Stanley Hoffman, 1970), ou que o modelo bipolar surgido depois da Segunda Guerra Mundial deu lugar a um modelo pentagonal (Silviu Brucan, 1977).

A dinâmica do poder mundial modificou-se sensivelmente nos últimos anos da era bipolar, na medida em que a importância relativa que se atribuía ao elemento militar do Poder diminuiu em benefício dos elementos econômico, tecnológico e político-diplomático.

Esta alteração da importância relativa dos elementos do Poder conduziu à passagem da fase da confrontação à fase da negociação nas relações entre as principais potências mundiais; fato que levou a maior parte dos analistas da política internacional a examinar os acontecimentos mundiais pela ótica de "cinco principais centros de poder”, associando às três superpotências (EUA, URSS e China) a Europa Comunitária, que ocupa o primeiro lugar no mercado mundial, e o Japão, a título de grande potência econômica.

De fato, ao mesmo tempo que a recessão econômica da década de 1970 fazia sentir aos responsáveis das nações industrializadas que o centro nevrálgico do sistema econômico internacional se havia deslocado para o Médio Oriente e que as economias nacionais eram cada vez mais interdependentes, assistiu-se à transformação da conjuntura política mundial: o sistema bipolar, caracterizado pelo equilíbrio do terror resultante do antagonismo Leste-Oeste, que requisitou as energias e esterilizou as imaginações criadoras, deu lugar a um sistema pentagonal, em que, ao lado dos EUA, da URSS e da China, aparecem o Japão e a Comunidade Europeia como interlocutores importantes no diálogo internacional, e o qual evoluiu aceleradamente, para um sistema multipolar das relações internacionais.

Do ponto de vista das relações Leste-Oeste, a ordem bipolar foi posta em causa, em primeiro lugar, pelo cisma soviético-chinês, e, em segundo lugar, 
pela dificuldade crescente dos EUA em controlar o conjunto do mundo não comunista.

Como observou Marie-Claude Smouts (1980), “o crescimento espectacular do Japão e da Alemanha foi marcado por uma capacidade comercial que, depois dos anos sessenta, pôs estes países em concorrência com os EUA (...) Para eles, o problema tem sido resistir às pressões americanas tendentes a utilizá-los como locomotiva para relançar a economia mundial sem prejuízo para os interesses norte-americanos. Apesar da insistência dos EUA para que eles reapreciem a sua moeda relativamente ao dólar e relancem a sua expansão, estes dois países têm resistido e mostraram que eram donos e senhores da sua política econômica e monetária”. E, de acordo com Servan-Schreiber, “a era do desafio americano, da supremacia de um só país nos domínios econômico e científico, terminou. Novos pólos surgiram: a Comunidade Europeia, o Japão e o Sudeste Asiático, o Golfo da Arábia. O mundo é multipolar” (1980, 353).

O equilibrio do terror, gerado entre as duas superpotências, possibilitou um importante espaço de manobra às médias potências e deu origem ao policentrismo nuclear do qual emergiu uma multipolaridade nuclear efetiva: a GrãBretanha, a França, a Alemanha, a China, o Japão, a Índia, a África do Sul, o Brasil, a Argentina e Israel adquiriram um potencial nuclear considerável, fato que lhes permite desempenhar um papel mais ativo na evolução da conjuntura mundial.

Por outro lado, as diversas potências nucleares pertencem simultaneamente a organizações de caráter universal e a organizações de âmbito continental ou regional: subscreveram a Carta das Nações Unidas, por um lado, e fundaram ou tornaram-se membros de organizações regionais, tais como a Organização dos Estados Americanos (OEA), a Organização da Unidade Africana (OUA), a Associação das Nações do Sudeste Asiático (ASEAN), a Organização dos Países Exportadores de Petróleo (OPEP), a Organização do Tratado do Atlântico Norte (OTAN) e o Tratado de Assistência Mútua da Europa Oriental (Pacto de Varsóvia) - já dissolvido - a União da Europa Ocidental (UEO), a Organização de Segurança e Cooperação na Europa (OSCE), etc.

Tudo isso fez com que o sistema internacional se tornasse o mais descentralizado da história moderna.

A crescente dispersão do potencial nuclear por Estados de considerável importância econômica e estratégica é um fator relevante para a formação de novos espaços (blocos). De resto, foi com base neste fator e na proliferação de organizações regionais e subregionais, e partindo de uma análise histórica, que Herman Kahn e Anthony J. Wiener (1972) profetizaram que, no ano 2000, o mundo estaria dividido numa série de blocos. Segundo eles, “os seguintes grandes blocos são plausíveis: a) Bloco Norte-Americano (ou Estados Unidos-Atlântico Norte, ou Estados Unidos-Atlântico-Pacífico); b) Bloco Europeu (mais provavelmente as 
nações da CEE, talvez incluindo outros Estados); c) Bloco Latino-Americano; d) Bloco Soviético; e) Bloco Africano; f) Bloco Árabe; g) Bloco Indiano; h) Bloco Chinês; i) Outros.

Os seguintes blocos menores também poderão facilmente existir, ou ser considerados desejáveis: j) Bloco Balcânico; l) Série Sulina (Turquia, Afeganistão, Paquistão); m) Bloco Malásia-Indonésia-Filipinas”.

A evolução do sistema mundial de poderes nas últimas duas décadas é, simultaneamente causa e efeito da modificação política e geográfica do mundo, pois a paisagem geopolítica do chamado mundo pós-moderno é muito diferente daquela que se observava na década de 1950, em pleno auge da guerra fria.

Naquela época, conforme nos revela Pedro Geiger (1994), “o mapa caracterizava-se por:

a) um conjunto de Estados interligados por diversos pactos políticomilitares, sob a liderança dos Estados Unidos;

b) um conjunto de Estados formando o bloco liderado pela URSS;

c) o bloco de Estados designados não-alinhados, muitos deles tendo-se tornado independentes apenas depois da II Grande Guerra;

d) os países derrotados do antigo Eixo;

e) poucos países neutros, como os da Escandinávia e a Suíça;

f) remanescentes coloniais subordinados a países europeus”.

Porém, o novo mapa apresenta características bem diferentes, das quais se destacam:

“a) - A multiplicação de Estados independentes e a sua enorme diversidade em dimensões geográficas e populacionais;

b) - A tendência para a formação de grandes blocos econômicos (zonas de comércio livre e mercados comuns), sendo a União Europeia o mais avançado no processo de integração;

c) - A reafirmação dos EUA como superpotência, na sequência da implosão da URSS e da desintegração do bloco soviético;

d) - A divisão entre países detentores e não detentores de armamento nuclear, e a preocupação em impedir a proliferação de armas atômicas, tendo-se generalizado os conceitos de 'governos responsáveis' e de 'governos não-responsáveis', que correspondem respectivamente a 'sociedades abertas e governos democráticos' e a 'sociedades fechadas e governos autoritários';

e) - O esvaziamento do Movimento dos não alinhados, em consequência da supressão da bipolaridade e da desintegração da Jugoslávia, país impulsionador e fundador do respectivo movimento;

f) - A globalização dos movimentos de capitais, de pessoas, de serviços e das técnicas, que se expressa nos fluxos financeiros creditados ou 
debitados a grandes distâncias quase instantaneamente, no envolvimento crescente de milhões de pessoas na prática do turismo internacional, com o desejo de superar o lugar e viver o mundo, e na circulação instantânea da informação pelas redes de comunicação que cobrem todo o Globo terrestre.”

A nova geopolítica do mundo, resultante da rápida transformação da conjuntura internacional nos anos de 1989/1990, tem suscitado muitas interrogações quanto à tendência evolutiva do sistema mundial de poderes e aconselha uma certa prudência aos analistas da política internacional que hesitam em tipificar o atual sistema mundial em sistema multipolar, ou multiblocos ou em sistema unimultipolar. Com efeito, Stanley Hoffman (1990) acredita no estabelecimento de um mundo multipolar formado por diferentes pólos e recursos de poder, argumentando que a Rússia se mantém como uma importante força militar, a China é uma potência demográfica, a Alemanha e o Japão são centros de poder econômico e financeiro, e os EUA dispõe de poder econômico e militar; enquanto Samuel Huntington (1991) prognostica um mundo unimultipolar, sendo os EUA a única superpotência, coexistindo com outros poderes intermediários, tais como: o Japão, a Alemanha, a França, o Reino Unido, a China, a CEI (Comunidade de Estados Independentes), e alguns países do chamado Terceiro Mundo, como a Índia.

A multipolaridade para que tem evoluído a comunidade internacional, a partir do fim dos anos sessenta, é muito diferente do sistema multipolar do equilíbrio de forças do século XIX e do sistema de segurança coletiva multipolar que vigorou entre as duas guerras mundiais. Nestes, a polarização fazia-se à volta dos Estados (as grandes potências da época) que tinham um poderio mais ou menos equilibrado. No sistema internacional atual a polarização faz-se à volta das grandes potências econômicas e político-militares e dos agrupamentos das médias e pequenas potências. Por isso não falta quem caracterize o sistema internacional como um sistema multiblocos, partindo do princípio de que as grandes potências estão rodeadas de Estados satélites ou de Estados clientes.

O sistema internacional multiblocos, que reflete concretamente a realidade internacional do nosso tempo, alia a multipolaridade do sistema de equilíbrio das forças ao fenômeno do bloco específico da bipolaridade. O bloco é, pois, um parceiro do equilíbrio de forças que se constitui de diversos centros políticos mais ou menos autônomos.

Mesmo não se tendo concretizado plenamente a profecia de Kahn e Wiener no ano 2000, o sistema mundial de poderes no início do século XXI caracteriza-se pela coexistência de um sistema de multiblocos econômicos com um sistema políticomilitar unipolar sob a liderança dos EUA. Todavia, as potências ascendentes, particularmente o Brasil, a China Popular, o Japão, a Índia, esforçam-se por aproximar-se dos grandes parceiros do poderio mundial e exigem dividendos políticos 
pela sua participação no diretório internacional, que no alvorecer do século XXI, é constituído pelos Estados Unidos da América, Rússia, Alemanha (União Europeia), Brasil, República Popular da China, Japão e Índia, desempenhando cada um destes países o papel de Estado-Diretor na sua área de interesses especiais.

\section{O Brasil no contexto do sistema mundial de poderes}

No cenário atrás descrito, que caracteriza o sistema mundial do início do século e determina o contexto das relações internacionais, que papel cabe ao Brasil? Que lugar ocupa este país na escala mundial de poderes?

A resposta a estas interrogações exige a inventariação dos fatores, dos elementos, que permitem a alguns atores (Estados) impor a sua vontade no diálogo internacional, ou que os tornam mais responsáveis aos olhos da opinião pública mundial, e conduz, por sua vez, a outras interrogações, como, por exemplo: Qual a natureza do poder internacional dos Estados? Quais os elementos que devem ser (ou têm sido) considerados para comparar o poderio dos Estados? Será que à igualdade jurídica dos Estados, plasmada na Carta das Nações Unidas, corresponde, de fato, uma igualdade funcional no contexto das relações internacionais? Ou os Estados são funcionalmente desiguais, em virtude de serem grandes ou pequenos, ricos ou pobres, desenvolvidos ou subdesenvolvidos, com ou sem poderio nuclear, etc?

No domínio das relações internacionais, confunde-se, muitas vezes, poder com força. Porém, os dois conceitos são distintos e respeitam a realidades diferentes: o poder é desde logo e principalmente um instrumento político, ao passo que a força, no sentido físico da violência, só intervém se os outros meios de persuasão e de pressão não puderem sustentar a linha de ação prevista pelo Estado que exerce o poder. A força deve ser considerada sempre como o último argumento no diálogo internacional. O poder nacional tem, no entanto, um valor relativo - é um potencial cujo valor real depende da sua utilização no plano político e na medida em que possa servir para alcançar um objectivo determinado.

Mas o que é que constitui o poderio dos Estados, ou seja, o potencial que lhe permite determinar os objectivos e mobilizar os meios de persuasão e de pressão e utilizar a força para os alcançar? Quais os recursos que os Estados podem mobilizar e colocar ao serviço da sua ação diplomático-estratégica? Enfim, quais são os elementos do poder mundial dos Estados?

Na ótica de Jacques Huntzinger, os autores que se debruçaram sobre esta matéria têm referido "mais ou menos os mesmos elementos: a extensão do território, o volume e a estrutura da população, os recursos econômicos, as capacidades industriais, a condição de preparação militar, o grau de integração social, a moral nacional, a estabilidade política do Estado" $(1991,90)$. E no entender de Palmer e 
Perkins, são sete os fatores contributivos para o poder dos Estados: “situação geográfica, recursos naturais, desenvolvimento tecnológico, população, ideologia, moral do país e valor dos dirigentes” $(1957,35)$.

Por outro lado, um teórico do poder - Georges W. Ball $(1968,5)-$, considerando que cada época tem a sua escala de valores, chegou à conclusão, nos finais dos anos sessenta, de que só uma sociedade homogênea com cerca de 200 milhões de habitantes, dispondo de um rendimento anual de pelo menos 300.000 milhões de dólares, de uma tecnologia altamente avançada e de armazenamento moderno compreendendo dispositivos militares aperfeiçoados e eficazes, pode classificar-se de potência mundial.

Estes diversos elementos são considerados quase unanimemente como fontes prováveis do poder dos Estados, pois os diferentes critérios utilizados em estudos comparados do poder nacional classificam os países em função da extensão e situação geográfica, do produto nacional bruto, dos recursos naturais e sobretudo da força militar. Sabe-se, aliás, que o volume dos recursos físicos, materiais e humanos que o Estado pode mobilizar ao serviço da sua política diplomáticoestratégica estabelece o seu estatuto no seio da comunidade internacional. Por isso alguns autores, atendendo à combinação das capacidades econômicas e militares dos Estados, estabeleceram a trilogia clássica que agrupa os países em grandes potências, potências médias e pequenas potências. Outros autores, predominantemente anglo-saxônicos, conceberam quatro elementos - dimensão do território, população, capacidade econômica e capacidade militar - para agrupar os países em quatro categorias: superpotências, grandes potências, potências médias e pequenas potências. E outros autores ainda classificam os Estados em "superpotências, potências secundárias, médias potências, potências regionais, pequenas potências, Estados dependentes e Micro-Estados” (Huntzinger, 1991, 112).

São pois diversos os elementos, os fatores, que podem ser utilizados para proceder à classificação internacional dos Estados: fatores de ordem econômica, fatores de natureza militar, fatores de índole geográfica e demográfica, fatores de desenvolvimento tecnológico, fatores de integração e coesão social, etc. E, conforme o critério adotado de incidência em um ou outro desses fatores, assim teremos hierarquias diferentes dos Estados. Por exemplo, se atentarmos nos fatores de ordem econômica, teremos de considerar grandes potências econômicas, não só os EUA e a Rússia, mas também o Japão, a Alemanha, o Reino Unido, a França, a China, a Itália e o Canadá. Mas, se considerarmos os fatores de natureza militar, identificamos os EUA e a Rússia como superpotências, em virtude do seu arsenal bélico, da sua capacidade estratégica e do seu domínio do controlo dos armamentos, e depois encontramos algumas grandes potências: França, Reino Unido e eventualmente a Alemanha e outros países que dispõem de armamento nuclear (Brasil, Índia, Iraque, China). 


\section{Quadro 2 \\ Dimensões geográfica e demográfica de alguns países, em 1995}

\begin{tabular}{|c|c|c|c|}
\hline Países & $\begin{array}{l}\text { e) População } \\
\text { (milhares) }\end{array}$ & $\begin{array}{l}\text { (b) Superfície } \\
(\mathrm{Km} 2)\end{array}$ & Índice $\frac{(\mathrm{a})+(\mathrm{b})}{2}$ \\
\hline China................................. & 1.225 .000 & 9.596 .961 & 617,2 \\
\hline 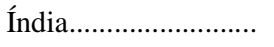 & 914.000 & 3.267 .590 & 458,6 \\
\hline E.U.A. ………........... & 260.500 & 9.363 .123 & 134,9 \\
\hline 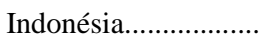 & 198.000 & 1.913 .000 & 99,9 \\
\hline 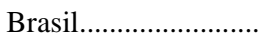 & 159.000 & 8.511 .123 & 83,7 \\
\hline Rússia............................ & 150.000 & 17.075 .400 & 83,5 \\
\hline Paquistão........................ & 131.400 & 803.943 & 66,1 \\
\hline 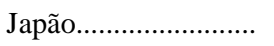 & 126.000 & 377.750 & 63,1 \\
\hline 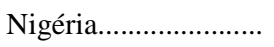 & 123.000 & 923.768 & 61,9 \\
\hline México.......................... & 91.800 & 1.967 .183 & 46,8 \\
\hline Alemanha........................ & 80.900 & 357.050 & 40,6 \\
\hline Turquia............................ & 60.800 & 780.576 & 30,8 \\
\hline 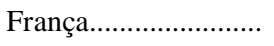 & 57.800 & 547.026 & 29,2 \\
\hline Itália.............................. & 57.900 & 301.225 & 29,1 \\
\hline 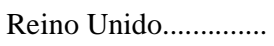 & 57.600 & 244.046 & 28,9 \\
\hline África do Sul............... & 41.700 & 1.221 .037 & 21,5 \\
\hline Espanha........................... & 40.000 & 504.782 & 20,3 \\
\hline Argentina........................ & 33.800 & 2.766 .700 & 18,3 \\
\hline Canadá............................. & 28.000 & 9.976 .139 & 14,0 \\
\hline 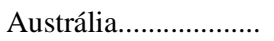 & 18.000 & 7.682 .300 & 7,8 \\
\hline
\end{tabular}

Fonte: L'État du Monde, Éditions La Découverte, 1996

E, se tivermos em atenção os fatores geográficos e demográficos e combinarmos a extensão do território com o volume da população, atribuindo a ponderação de $50 \%$ a cada uma destas variáveis, chegamos à seguinte ordenação dos principais países do Globo: China, Índia, EUA, Indonésia, Brasil, Rússia, Paquistão, Japão, Nigéria, México, Alemanha, Turquia, França, Itália, Reino Unido, África do Sul, Espanha, Argentina, Canadá, Austrália.

Por outro lado, se o critério de classificação da hierarquia dos Estados incidir no desenvolvimento tecnológico, no nível de vida das populações e na estrutura das relações de produção em nível internacional, a ordenação do poderio dos Estados é bem diferente da que resulta da combinação da dimensão populacional com a extensão geográfica. A este respeito é de sublinhar um importante estudo elaborado por Robert Cox e Harold Jacobson (1977), os quais, partindo do princípio de que 
não possível definir corretamente o sistema mundial das relações de força se não se entrar em linha de conta com a estrutura das relações de produção existentes no mundo, apresentaram uma classificação dos países da época à volta de cinco categorias. Para estes autores, a internacionalização da produção estabelece, à escala mundial, uma divisão do trabalho, segundo a qual o progresso tecnológico está concentrado numa zona central, enquanto a produção dos bens de consumo tende cada vez mais a situar-se nas zonas periféricas. A zona central detém os níveis de comando, através das sociedades multinacionais. E entre o centro e a periferia encontram-se zonas semiperiféricas que compreendem os países que se batem por não perder a possibilidade de se integrarem no grupo dos países do centro.

Cada elemento deste sistema mundial deve ser definido de acordo com a sua função no quadro global das relações de produção. Por outro lado, as funções podem ser consideradas numa perspectiva geográfica, correspondendo algumas funções específicas a determinado grupo de países. Logo os conceitos de centro e periferia são, ao mesmo tempo, funcionais e geográficos.

Do ponto de vista das relações de produção internacionais, o sistema mundial da época (1977) permitia, em termos de estrutura e evolução, uma divisão em cinco categorias de países.

Em primeiro lugar, encontravam-se os países desenvolvidos, cuja sociedade já atingia o nível pós-industrial. É nestes países que geralmente se situavam as sedes das sociedades multinacionais e se concentrava a investigação científica e o desenvolvimento tecnológico. Esse grupo de países, que compreendia os EUA, o Japão e alguns países da Europa Ocidental, constituía o centro, ocupando os EUA o centro do centro, e representava cerca de $10 \%$ a $15 \%$ da população mundial.

Na Segunda categoria, encontrava-se um grupo de países altamente industrializados. Naquele tempo (1977) era sem dúvida o grupo dos países europeus membros do Conselho de Assistência Mútua Econômica (CAME) que constituía o elemento mais importante desta categoria - a dos semiperiféricos - a qual englobava também os países capitalistas industrializados que ainda não tinham ascendido à posição dos pós-industrializados. Estes países, que contavam com $15 \%$ a $20 \%$ da população mundial, procuravam conciliar a necessidade de estabelecer uma ligação cada vez mais estreita com os países produtores do mundo inteiro com a determinação de preservarem a sua autonomia de desenvolvimento, a fim de atingirem o nível das sociedades pós-industriais pelos próprios meios.

Em terceiro lugar, tínhamos os países cujo desenvolvimento capitalista dependente, assentava numa indústria controlada pelos países pós-industriais. Tratava-se nomeadamente de países relativamente pouco desenvolvidos como a Argentina, o Brasil, a Espanha, a Grécia, o México, Portugal, a República da Coreia, Singapura, etc. Abrigando cerca de $20 \%$ da população mundial, estes países 
laboravam por conta dos países mais desenvolvidos, tornando-se os principais fornecedores de mão-de-obra de que estes necessitavam.

Na Quarta categoria, encontravam-se os países subdesenvolvidos que agrupavam cerca de $25 \%$ da população mundial e tinham perspectivas de desenvolvimento bastante limitadas no contexto atual das relações de produção, ou, por outras palavras, no quadro da estrutura mundial do poder social.

Numa Quinta categoria, integrava-se a República popular da China onde vivia quase um quarto da população mundial. Segundo os indicadores estatísticos, a China era um país em vias de desenvolvimento. Mas não podia ser assimilada aos países pobres e deserdados que constituíam a categoria anterior. Recusando uma economia do tipo capitalista dependente, procurava desenvolver-se de maneira autônoma. No entanto, a longo prazo, duas hipóteses se colocavam, nenhuma delas passível de exclusão: a de a China vir a ser um país do tipo semiperiférico, em virtude do desenvolvimento das suas relações com o exterior, ou a de se tornar um contramodelo capaz de atrair os países descontentes com o modelo de funcionamento do sistema mundial de produção.

As três primeiras categorias de países, que abrigavam cerca de metade da população do globo, reagrupavam os elementos mais estreitamente integrados ou os mais interdependentes do sistema mundial das relações de produção.

A outra metade da população mundial vivia em países menos estreitamente integrados nesta estrutura. Estes países não eram essenciais ao funcionamento do sistema. A sua mão-de-obra não era solicitada pelos países do centro, e estes só em proporções muito reduzidas exploravam os seus mercados. O seu descontentamento resultante de um estado de frustração econômica não punha em perigo o equilíbrio do sistema, porque este subsistia à custa das três primeiras categorias de países.

Depois da publicação do estudo de Robert Cox e Harold Jacobson, a estrutura das relações de produção internacionais não sofreu grandes alterações. A República Popular da China continua a ser um país em vias de desenvolvimento, onde vive quase um quarto da população mundial (1225 milhões de habitantes em 1995), encontrando-se numa fase de hesitação entre continuar arraigada a uma ideologia conformadora de um Estado gestor de uma economia de direção central, ou enveredar por um caminho que a aproxime do modelo econômico ocidental. Os países subdesenvolvidos não melhoraram a sua posição relativa no contexto das relações de produção internacionais; pelo contrário, nas últimas duas décadas, viram até alargar-se o fosso que os separa dos países desenvolvidos e pósindustrializados. E o grupo dos países pós-industrializados continuam a ocupar o centro da estrutura mundial das relações de produção, controlando o desenvolvimento tecnológico, a investigação científica, os investimentos financeiros e as trocas comerciais. 
É certo que a queda do muro de Berlim, a desintegração da URSS e a transformação do sistema econômico dos países da Europa Central e do Leste, atrasaram o processo de evolução de alguns países dessa área geográfica para a fase da pós-industrialização, e que alguns países capitalistas dependentes conheceram um razoável nível de desenvolvimento nos últimos vinte anos (Argentina, Brasil, Coréia, Espanha, Portugal, Singapura), deixando de ser meros fornecedores de mão-de-obra e destinatários dos produtos de tecnologia de ponta. Mas a estrutura mundial das relações de produção não sofreu alterações significativas, podendo mesmo afirmar-se que as cinco categorias de países, identificadas por Robert Cox e Harold Jacobson nos finais da década de setenta, continuam hoje a subsistir, embora tenha havido variações no conjunto dos países que constituem a Segunda e terceira categorias, passando muitos países que integravam o Conselho de Assistência Mútua Econômica (COMECON), dissolvido em 28 de Junho de 1991, à categoria de semiperiféricos dependentes, por troca com alguns países que pertenciam à terceira categoria, mas que se tornaram altamente industrializados. Daí que nos pareçam pertinentes as seguintes palavras de Olivier Dollfus: "nunca na história da humanidade houve tamanha concentração de poder nuns poucos lugares nem tamanha separação e diferença no interior da comunidade humana" $(1994,34)$. O significado destas palavras exprimiu-o o autor no seguinte texto:

"No final do século $\mathrm{XX}$, os poderes que atuam sobre o mundo e as inovações que o transformam localizam-se num número limitado de lugares: megalópoles da América do Norte, a do nordeste e a da Califórnia, a do Japão, centrada em Tóquio, a da Europa Ocidental, entre a planície do Pó e a bacia de Londres, englobando a ilha parisiense. Aí, $5 \%$ da população mundial vive em $0,4 \%$ da superfície das terras. É aí que se localiza a grande maioria das 500 maiores empresas financeiras e industriais, os governos e as instituições que pesam sobre o mundo: Casa Branca e Pentágono, o Banco Mundial e o Fundo Monetário Internacional em Washington; as Nações Unidas e Wall Street em Nova York; os centros financeiros de Tóquio, Frankfurt e Londres, as grandes agências de informação que tratam e difundem os acontecimentos do mundo; e, em Londres, a Reuter, que monopoliza as informações financeiras. Os membros do G7 (Grupo dos Sete), aí residem, como os presidentes e os primeiros-ministros, que frequentam as conferências de cúpula. Dos novos conhecimentos, $90 \%$ se elaboram nos laboratórios dos países onde se encontram essas megalópoles.

Nesses pólos do SM (sistema mundial), estratégias e decisões repousam num tratamento maciço e instantâneo de informações públicas e confidenciais coletadas em todo o Mundo. No anel das redes que cinge a Terra nas latitudes médias do hemisfério norte, circulam 98\% das informações financeiras, e os tráficos aéreos são aí mais intensos. Os contatos diretos entre dirigentes conservam toda a sua importância, sem embargo da fluidez e da diversidade de meios de comunicação: é nesse anel que se deslocam os "novos nómadas" que dirigem o mundo" (Dollfus, 1994, 34-35). 
É, pois, evidente que a hierarquia internacional do Estado decorrente da estrutura mundial das relações de produção não se identifica com a que resulta da sua extensão geográfica e da dimensão da sua população, nem esta corresponde à ordenação dos Estados com base na sua força militar e capacidade estratégica. Quer dizer que é necessário Ter em conta todos estes fatores (geográficos, demográficos, econômicos, militares) para estabelecer uma hierarquia internacional dos Estados. Porém, a estes fatores deve-se acrescentar um outro elemento importante: a coesão social e ideológica da coletividade. Com efeito, um Estado pode ocupar uma grande superfície geográfica, Ter um elevado volume de população e dispor de recursos naturais, de um rendimento econômico razoável e de um elevado arsenal bélico, mas, se não houver uma forte integração social e uma elevada coesão política e ideológica da sua população, dificilmente poderá mobilizar os recursos naturais, econômicos e bélicos para se afirmar no diálogo internacional.

O poder internacional dos Estados deriva, portanto, de diversos fatores. E, para proceder à sua classificação numa escala internacional de poderes, é necessário considerar vários elementos constitutivos da sua capacidade de ação, a saber:

a) Extensão e situação geográfica (geoestratégica);

b) População e coesão social, política e ideológica;

c) Recursos naturais (fontes energéticas e minerais nobres);

d) PNB e desenvolvimento tecnológico;

e) Força militar e capacidade estratégica.

Considerando o conjunto destes elementos constitutivos da capacidade de intervenção dos Estados, é possível hierarquizar os países em superpotências, grandes potências, potências médias, pequenas potências e micro-Estados (como os Estados exíguos da Europa e os pequenos países das Caraíbas e do Pacífico), ou, adotando outra perspectiva, classificá-los em potências mundiais, potências regionais e potências locais. Nesta perspectiva, são potências mundiais os Estados com capacidade para reagir a quaisquer acontecimentos internacionais, e que dispõem de meios materiais, econômicos e humanos para intervir em qualquer parte do globo e influenciar os outros Estados e a dinâmica das relações internacionais; são potências regionais os Estados que, por razões históricas, econômicas e culturais, têm possibilidade de influenciar os outros Estados, situados na sua região ou em outras áreas geográficas e são potências locais, os Estados com capacidade de ação na sua área envolvente.

Atendendo aos fatores constitutivos do poder internacional dos Estados atrás numerados e tendo em conta a hierarquia dos Estados daí decorrente, não é difícil perceber que o Brasil ocupa um lugar de destaque nesta escala hierárquica. Com efeito, ocupando uma área geográfica de $8.511 .123 \mathrm{Km}^{2}$, compreendendo 
uma população superior a cento e sessenta milhões de habitantes (159 milhões em 1995), dispondo de um PIB de 866.827,5 milhões de reais (1997), cerca de 481.570,8 milhões de dólares, desfrutando de enormes recursos naturais (fontes energéticas e minerais nobres) e de um razoável nível de desenvolvimento tecnológico, ocupando relevante situação geográfico-estratégica, reforçada pela sua posição preponderante no seio do Mercosul, na ALADI (Associação Latino-Americana de Desenvolvimento e Integração) e na CPLP (Comunidade dos Países de Língua Portuguesa), a coesão social e estabilidade política de que desfruta permitem-lhe exercer uma certa influência na evolução da conjuntura mundial. Por conseguinte, os recursos naturais e humanos, a situação geoestratégica e as potencialidades de desenvolvimento tecnológico são fatores que definem o Brasil como uma grande potência contemporânea e lhe prognosticam um importante papel no contexto das relações internacionais e no sistema mundial de poderes do início do séc. XXI, que será tanto mais importante quanto este país souber compatibilizar os desígnios nacionais com os interesses e objectivos dos blocos regionais em que está inserido e dos quais é membro do destaque.

\section{Conclusão}

A reflexão feita nas páginas anteriores sobre o sistema mundial de poderes e o papel e importância do Brasil no contexto das relações internacionais e do sistema mundial permite-nos concluir o seguinte:

a) Graças à revolução tecnológica e científica do último quartel do século XX, o sistema mundial de poderes passou da bipolarização flexível para um sistema multipolar (ou multiblocos), se o acento tônico é colocado nos fatores de incidência econômica, ou para um sistema unipolar, se a tônica assentar nos fatores político-militares e diplomáticoestratégicos.

b) No contexto das relações internacionais e do sistema mundial de poderes, coexiste a igualdade jurídica dos Estados, plasmada nos textos dos principais tratados internacionais, com a desigualdade funcional, decorrente de um conjunto de fatores que determinam a sua posição na escala internacional de poderes e permite classificá-los em superpotências, grandes potências, potências médias, pequenas potências e micro-Estados.

c) Na hierarquia internacional dos Estados, o Brasil ocupa um lugar de grande potência, com capacidade para influenciar o comportamento de outros Estados. E a sua inserção no Mercosul, na ALADI e na CPLP, conjugada com as suas ligações históricas e culturais ao espaço 
atlântico, proporcionam-lhe condições altamente favoráveis para afirmar a sua presença no diálogo internacional e exercer maior influência na evolução da conjuntura mundial.

Dezembro de 2000

\section{Bibliografia}

ARON, Raymond. Paix et Guerre entre les Nations. Paris, 1962.

BALL, Georges W. The Discipline of Power. Boston: Litle Brown, 1962.

BRUCAN, Silviu. “As Noções de Poder e de Conflito”, in Revue International des Sciences Sociales (UNESCO), Vol.XXIX, nº1, 1997, pp. 125-149.

DOLLFUS, Oliver. “Geopolítica do Sistema Mundo”, in Fim do Século e Globalização (obra coletiva), São Paulo: Editora Hucitec, 1994.

GEIGER, Pedro. “Mapa do Mundo Pós Moderno”, in Fim do Século e Globalização (obra coletiva), São Paulo: Editora Hucitec, 1994.

HOFFMAN, Stanley. "Internacional Organization and Internacional System”, in International Organization, XXIV, 3, 1970.

. “A New World and its Troubles”, in Foreign Affairs, 69(4), 115-122, 1990.

HUNTINGTON, Samuel. “America’s Changing Strategic Interests”, in Survival, XXXIII, Jan.Fev., 1991, pp. 3-16.

HUNTZINGER, Jacques. Introdução às relações Internacionais. Lisboa: PE-Edições, 1991.

KAHN, Herman e WIENER, Anthony J. L'An 2000, La Bible des Trente Prochaines Annés”, trad. franc Marabout Université, 1972.

KAPLAN, Morton. System and Process in International Politics. N.Y. Huntington, 1975.

MORGENTHAU, Hans. Politics Among Nations. New York, 1969.

PALMER, N.D. e PERKINS, H.C. International Relations: The World Community in Transition. $2^{\text {nd }}$ ed, Boston: Houghton Mifflin, 1957.

SERVAN-SCHREIBER, Jean-Jacques. O Desafio Mundial. Lisboa, Pub. Dom Quixote, 1980.

SMOUTS, Marie-Claude. “Nouveaux Centre de Pouvoir et Problématique de la Puissance”, in Reveu Française de Science Politique, Vol. 30, n²2, Paris, 1980, pp. 220 e sgs.

L’État du Monde (obra coletiva), Éditions la Découvert, 1996.

\section{Resumo}

O presente estudo caracteriza o sistema mundial de poderes, explica a sua evolução, inventaria os fatores que determinam a posição relativa dos Estados na escala hierárquica internacional e mostra qual a posição, o papel e a importância do Brasil no contexto das relações internacionais da conjuntura mundial do nosso tempo, concluindo-se que o Brasil pode ser considerado uma grande potência com capacidade para influenciar cada vez mais o comportamento de outros atores internacionais e, conseqüentemente, a evolução da conjuntura mundial. Para se chegar a esta conclusão, o desenvolvimento do estudo abordou a aplicação de 
análise sistêmica à comunidade internacional, a evolução dos sistemas mundiais de poderes, as características do sistema multipolar contemporâneo e o Brasil no contexto do atual sistema mundial de poderes.

\section{Abstract}

This study characterizes the world's system powers, explains his evolution, describes the factors that determinate the relative position of States in international hierarchy and shows the position, role and notability of Brazil in the context of present international relations. We conclude that Brazil can be considered a big potency, with capacity to influence more and more the behaviour of other international actors and, consequently, the world conjuncture evolution. To achieve this conclusion, the study refers to the application of systemic analysis to the international community, to the evolution of world's system powers, to the characteristics of contemporaneous multipolar system and the Brazil in the actual context of world's system powers.

Palavras chave: Brasil. Hierarquia internacional. Comunidade Internacional. Key words: Brazil. International Hierarchy. International Community. 